\title{
Research on the Current Situation of Children's Family Safety Education
}

\author{
Xiaohe Wang, Yadan Wang \\ Pingdingshan University, Pingdingshan, Henan Province, China
}

\begin{abstract}
As guardians of young children, parents have the responsibility to protect their lives, improve their safety skills, and cultivate their safety awareness. This study investigated the current situation of children's safety education and found that the current family safety education has overprotection problems. There are still some problems in the time, content and methods of parents' safety education for their children. The main reason is that parents have deviations in the concept of safety education, parents have insufficient understanding of children's physical and mental characteristics, and lack the corresponding safety knowledge and skills. For this reason, the research puts forward corresponding tests and suggestions to solve this problem.
\end{abstract}

Key words: early childhood education; safety education; family education

\section{Introduction}

The early childhood stage is a period of enlightenment education for children, and it is also the beginning of cultivating individual safety awareness and improving self-protection ability. The state issued the "National Family Education Guidelines" in February 2010 clearly pointed out: "Do a good job in safety education and reduce accidental injuries to children". As the primary guardian of the child and the main person in charge of family safety accidents, parents not only have the responsibility to ensure the safety of the child's life, but also have the obligation to educate and guide the child in safety. In addition, the effectiveness of safety education in kindergartens depends largely on the cooperation and participation of families. As an irreplaceable place to implement safety education for children, the family is an extension of safety education activities in kindergartens. Only by working closely and coordinating with kindergartens can we achieve better educational results.

\section{The Status Quo of Infant Family Safety Education}

In order to understand the development status of children's family safety education, the researchers conducted investigation and analysis by issuing questionnaires to children's parents and interviewing children's parents. The questionnaire used in this study refers to Cao Miaoyan's Hebei University master's degree thesis, "Study on the Status Quo of Parental Safety Education for Children Aged 3-6", and was appropriately modified and generated according to the actual situation of the region. A total of 225 questionnaires were distributed to parents of children in three kindergartens in Henan province, of which 200 were valid questionnaires, with a recovery rate of approximately $89 \%$. The content of the questionnaire includes the concept, content, timing and content sources, methods, channels of parent safety education and

Copyright (C) 2021 by author(s) and Frontier Scientific Research Publishing Inc.

This work is licensed under the Creative Commons Attribution International License (CC BY 4.0).

http://creativecommons.org/licenses/by/4.0/ 
the ways in which parents participate in kindergarten safety education. In addition, combined with the interview method, 15 parents of three kindergartens were interviewed to understand the concepts, content, timing, methods, ways, and reasons behind the behaviors of children's family safety education. By summarizing various information, the current status of family safety education for children is as follows:

\subsection{The concept of parent safety education}

Parents' awareness of the necessity of child safety education, parents' awareness of safety environment and safety education, and parents' protection of children's safety, reflect to a certain extent the parents' concept of children's safety education. Through interviews, it is found that parents' awareness of the importance of family safety education is mainly reflected in the following two aspects: first, parents attach importance to children's safety, and second, parents believe that family safety education is an extension of kindergarten safety education and have a good understanding of the necessity of safety education. In addition, most parents are aware of the importance of safety education and a safe environment. The survey on the "safety protection of children by parents" is as follows:

Table1. Protection of young children by parents

\begin{tabular}{cccc}
\hline Question & Options & Number of people & Percentage \\
\hline Do you restrict your & often & 83 & $41.5 \%$ \\
child's movement & sometimes & 107 & $53.5 \%$ \\
outdoors? & less likely & 10 & $5 \%$ \\
\hline
\end{tabular}

Regarding the question of "Outdoors, would you restrict your child's movement?", 41.5\% of parents said that they often restrict their children's movement, while $53.5 \%$ of parents said that they sometimes restrict their movements. It can be seen from the survey data that parents have a tendency to over-restrict children's behavior.

2.2 The content of safety education for children

Safety education in this study refers to the physical safety education of young children. It is divided into three categories: the first category is regular safety education, including protecting the safety of various parts of the body, traffic safety, and food hygiene and safety. The second category is emergency safety education, including prevention of scalding, lightning protection, drowning, abduction, and sexual assault. The third category is safety education in activities, including companion play safety, toy safety, etc. The survey results on the question "What safety education do you often explain to your children?" are as follows:

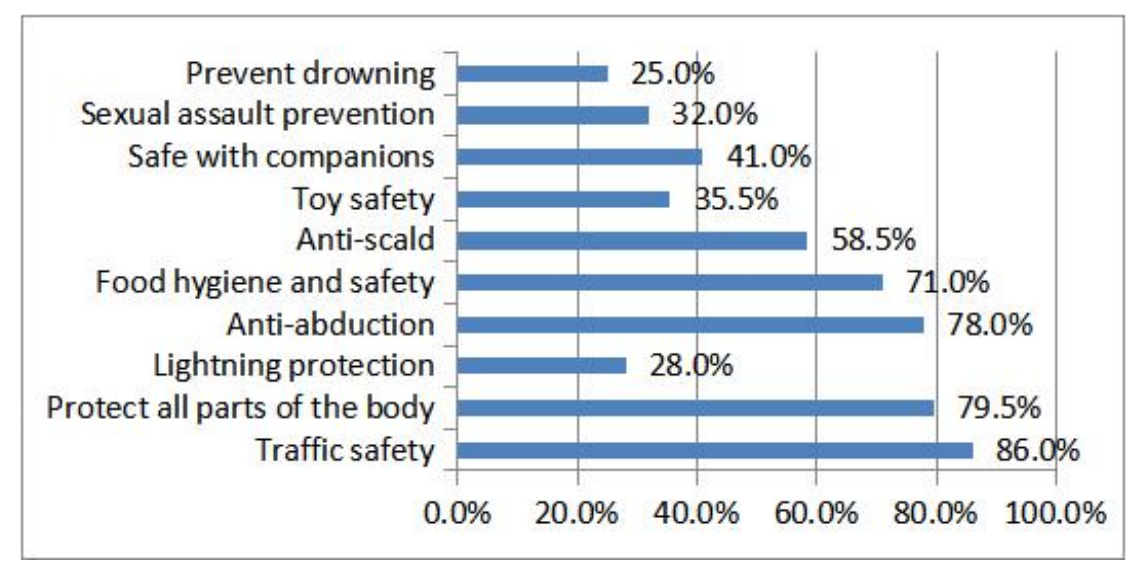

Figure 1. Safety knowledge that parents often explain to their children (multiple choices)

It can be seen from Figure 1 that the first four safety contents that parents often explain to their children are traffic safety, protection of various parts of the body, anti-abduction, food hygiene and safety. And the last four are lightning 
protection, drowning protection, sexual assault protection, and toy safety. Analysis data shows that the types of safety knowledge that parents explain to children are relatively diverse, but most of them are regular safety education and a small number of emergency education, ignoring the prevention of sexual assault education and safety education in activities.

2.3 The timing and content source of parents' safety education for children

Parents' early implementation of safety education can ensure the safety of children to a certain extent. The research survey on "When do you often use to educate young children on safety?" is as follows:

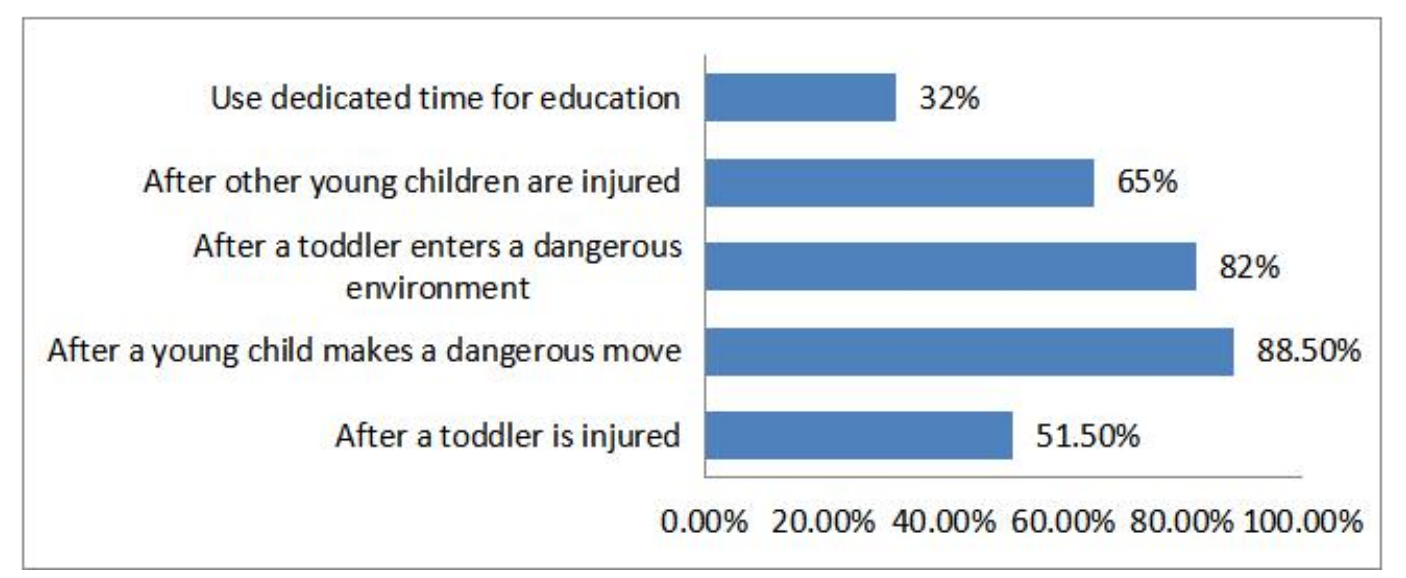

Figure 2. Timing of preschool safety education (multiple choice)

It can be seen from Figure 2 that $88.5 \%$ of parents give safety education to children after they are in danger, $82 \%$ are parents who educate their children in advance after entering a dangerous environment, and $65 \%$ are parents who educate children after other children are injured. Educational parents accounted for $51.5 \%$, and $32 \%$ of parents used special time to educate their children on safety. It can be seen that parent safety education is mostly carried out after children make dangerous actions, which lacks preventiveness.

How does the parent's safety knowledge come from? A survey on the sources of parental safety knowledge found that the sources of parental safety knowledge are relatively rich. The specific survey results are as follows:

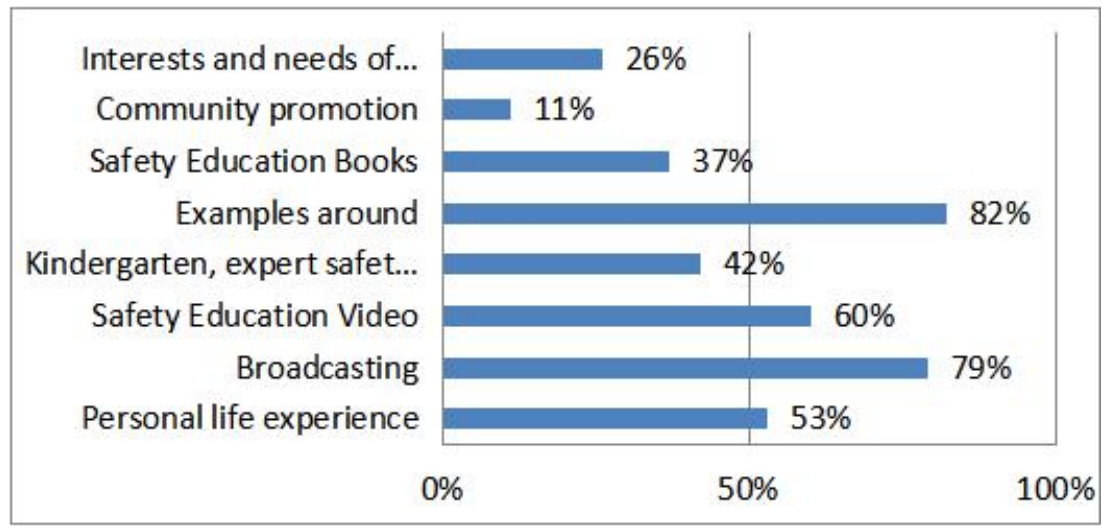

Figure 3. Sources of parental safety knowledge (multiple choices)

It can be seen from Figure 3 that the sources of parental safety knowledge are more extensive. Among them, there are more from examples, radio or television, accounting for $82 \%$ and $79 \%$ respectively. The results of the survey show that the source of parental safety is effective and life-oriented.

2.4 Methods for parents to implement safety education for children

A survey of parents' educational methods shows whether the parents' educational methods are scientific and reasonable. This study uses the questionnaire "What are the more commonly used education methods when you educate 
your children on safety?" to understand how parents implement safety education.

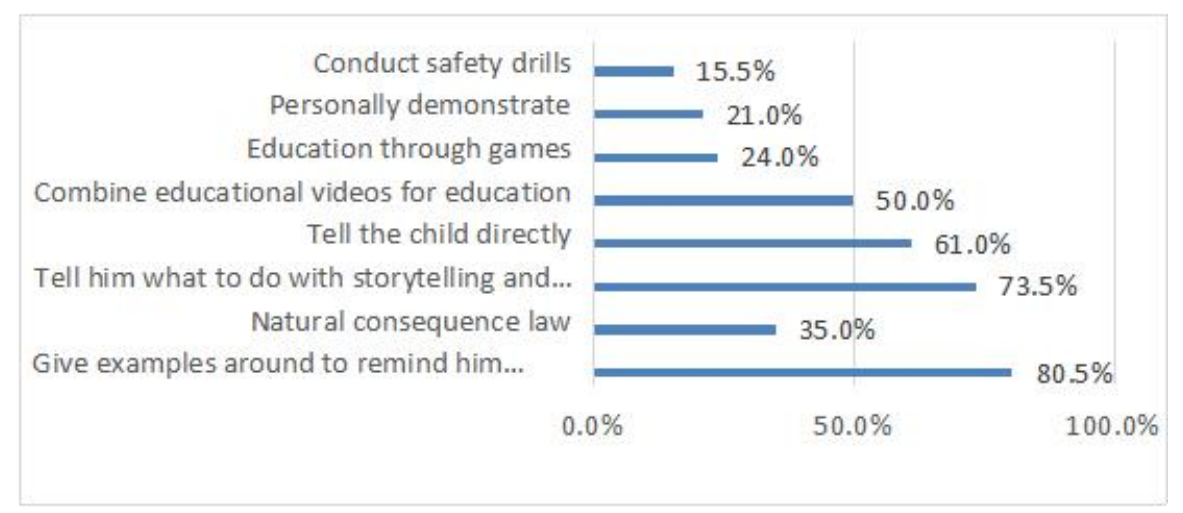

Figure 4. Methods used in parent safety education (multiple choices)

It can be seen from Figure 4 that $80.5 \%$ of parents remind them of what to beware of by giving examples around them. $73.5 \%$ of parents use storytelling and books to tell them what to do, $61 \%$ of parents will directly tell their children that this is not possible, and $50 \%$ of parents will combine education in the short film for education, $35 \%$ of parents will adopt the natural consequence method, $24 \%$ of parents will adopt the form of games, $21 \%$ of parents will use the method of personal demonstration, and $15.5 \%$ of parents will adopt the method of safety exercises. These data reflect that parents have flexible and diverse methods for children's safety education, but parents tend to educate them through language forms such as facts and reasoning, instead of using enough operating methods such as games, safety exercises, and personal demonstrations.

2.5 Ways for parents to implement safety education for children

Diversified safety education approaches can better realize the purpose of safety education. This study uses "what resources do you usually use to implement safety education for young children?" to understand the safety education approaches adopted by parents.

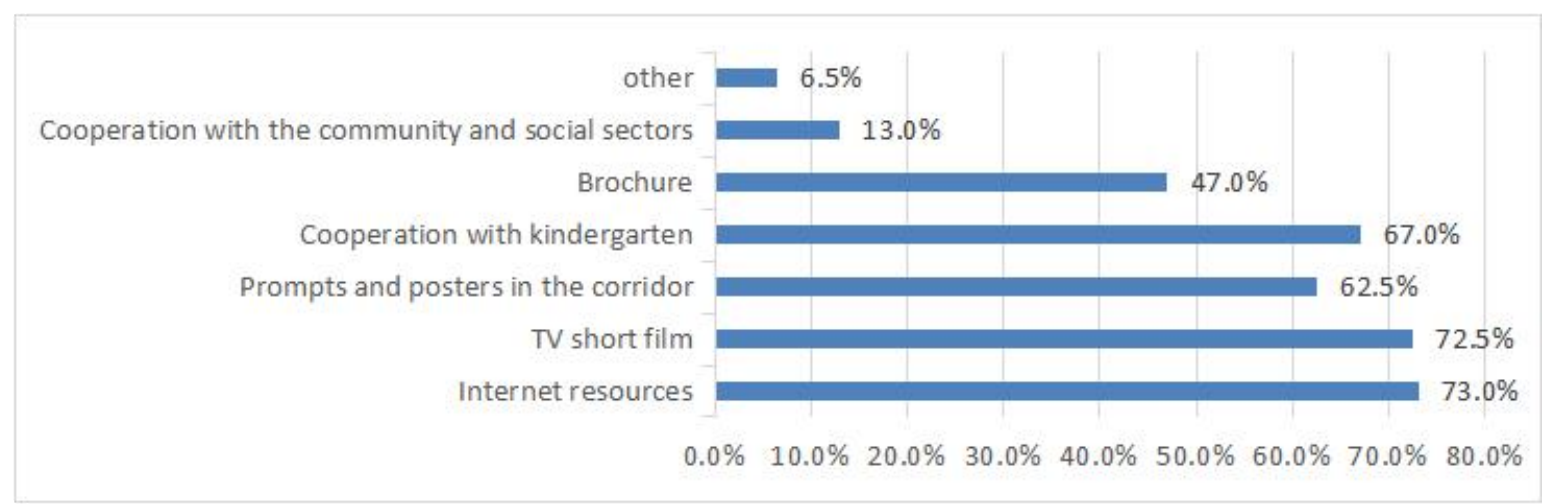

Figure 5. Parental safety education approach (multiple choices)

As shown in Figure 5,73\% of parents educate their children on safety through online resources, $72.5 \%$ of parents educate their children through TV short films, $62.5 \%$ of parents educate their children on safety based on prompts and posters in the corridor, and $67 \%$ parents educate young children through cooperation with kindergartens. $47 \%$ of parents use publicity brochures to educate young children, $13 \%$ of parents use cooperation with communities and social departments to educate young children, and $6.5 \%$ of parents use other means to educate children about preschool safety education. From these data, it can be seen that parents' safety education for children is mostly carried out through the internet, TV and cooperation with kindergartens.

2.6 Parents' understanding of homeland cooperation in safety education

The home and kindergarten are the two major places for children to educate. Parents' understanding of home safety 
education cooperation will be related to whether the goal of family safety education can be achieved efficiently. The investigation of "What do you usually do about children's safety education?" is as follows:

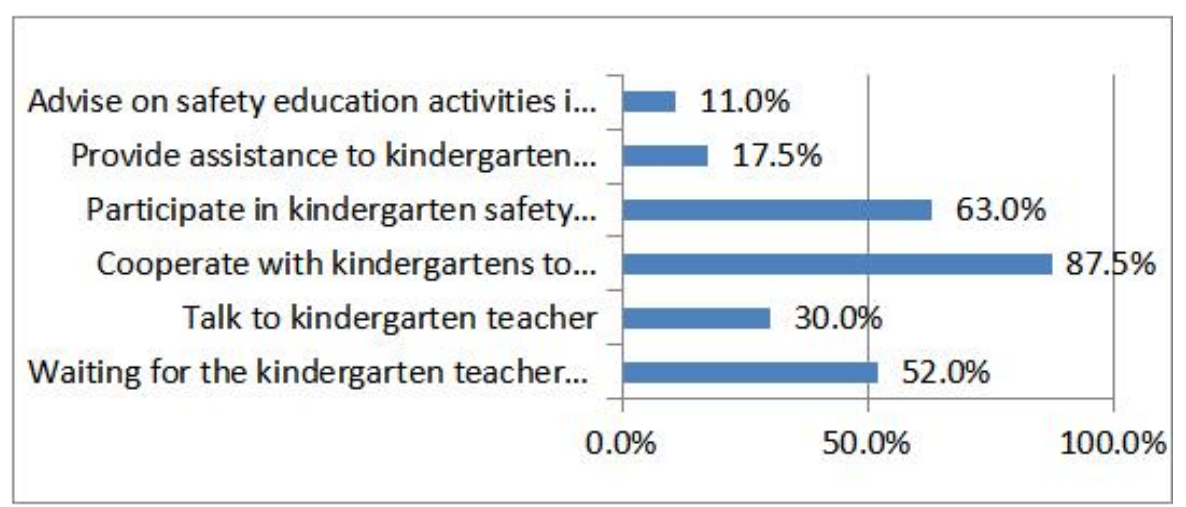

Figure 6. Ways of parents participating in kindergarten safety education (multiple choices)

The survey results show that $87.5 \%$ of parents will cooperate with kindergartens to jointly conduct safety education, $63.5 \%$ of parents will participate in kindergarten safety education activities, $17.5 \%$ of parents will provide help for kindergarten safety education, and $11 \%$ of parents will provide opinions on kindergarten safety education. It can be seen that parents often use cooperation and participation to participate in kindergarten activities.

The frequency of communication between parents and teachers can reflect the initiative of parents in the cooperation of children's safety education homes. Regarding "How often do you communicate with teachers about child safety education every month", the survey results show that parents who choose 0 times account for $32.5 \%$, and parents who choose 1 time account for $49 \%$. It can be seen that the frequency of communication between parents and teachers is relatively low.

Table 2. Number of exchanges between parents and teachers each month

\begin{tabular}{ccccc}
\hline Options & 0 & 1 & 2 & 3 times and above \\
\hline Number of people & 65 & 98 & 27 & 10 \\
frequency & $32.5 \%$ & $49 \%$ & $13.5 \%$ & $5 \%$ \\
\hline
\end{tabular}

\section{Problems in the Current Situation of Family Safety Education for Children}

\subsection{Parents overprotect young children}

In the questionnaire survey, all parents are aware of the necessity of safety education for children. In Table 1, 41.5\% of parents would restrict children's activities outdoors, which shows that parents tend to overprotect children. Parents often over-limit and intervene in children, which not only reduces children's participation and initiative in activities, but also hinders the development of children's physical coordination and athletic ability.

3.2 The timing of parent safety education is lagging

The most appropriate time for parents to implement safety education for young children is to educate in advance or use special time to carry out planned education. Figure 2 shows that $90.5 \%$ of parents educate their children after they make dangerous actions. It shows that the timing of parental safety education is lagging. Parents do not realize the important value of safety education for children in advance. They often educate children when they encounter safety problems, which weakens the education before activities that can play a preventive role.

\subsection{The content of parent safety education lacks comprehensiveness}

Parents themselves have a wealth of safety knowledge, which is the cornerstone of a smooth family safety education. Figure 1 shows that most parents pay more attention to common safety issues such as traffic safety, protection of various 
parts of the body, food hygiene and safety, anti-abduction and other life-related safety incidents, and pay more attention to safety and prevention in activities such as the safety of their peers and toy safety. However, there is less security attention to emergencies such as sexual assault and lightning protection.

\subsection{Poor safety education methods for parents}

Figure 4 shows that only $15.5 \%$ of parents will use safety drills to implement safety education for young children, $21 \%$ of parents will conduct safety education for children through personal demonstrations, and most parents' safety education methods are mainly oral, which is lack of practicality and operability.

3.5 Parents lack initiative in safe co-education activities

Table 2 shows that $32.5 \%$ of parents communicated with kindergarten teachers conducted 0 safety education communications within one month. And Figure 6 shows that only $30 \%$ of parents contact teachers for safety education. These show that parents lack initiative in safe co-education activities. Subsequent interviews also found that when parents participate in kindergarten safety education, cooperation is the main focus, and they seldom contact teachers for children's safety education.

\section{Strategies and Suggestions for Family Safety Education for Young Children}

The reason why parents have the above problems when they give children safety education is that, on the one hand, parents have errors in their own understanding of children's safety education, and they often treat children's safety issues with a passive and conservative concept. On the other hand, parents have insufficient understanding of the physical and mental characteristics of young children, and cannot carry out safety education in an appropriate way. In order to solve the current problems of safety education in family education and improve the effect of family safety education, the following strategies and suggestions are proposed.

\subsection{Establish a correct view of safety education}

Normally, parents are responsible for the safety of their children, and they always tell children to "be careful, it is dangerous!" Over time, children will become dependent in their lives. As everyone knows, no matter how careful parents are, they cannot foresee the dangers their children may encounter. Therefore, parents can not only create a safe environment for their children, but also urgently need to change the concept of safety education, turning negative means to ensure safety to positive means to teach safety. Parents should not only let their children master some basic life skills in daily life, and accumulate skills and methods to deal with dangers, but also closely integrate the cultivation of children's good living habits with teaching children to protect themselves. Parents should also establish a concept of homeland cooperation, because the establishment of children's safety awareness and the acquisition of safe behaviors are both affected by kindergarten education and family education, parents and teachers need to cooperate closely to grow together. As parents, they should take the initiative to take the responsibility of safety education, actively communicate with kindergarten teachers, and provide a strong backing for kindergarten safety education.

\subsection{Strengthen parents' own safety knowledge learning}

Today, with the development of the internet, parents can not only search the information they need online, but also use the resources at hand, such as the safety education platform tasks arranged by the kindergarten, the safety education lectures organized by the kindergarten, and the books recommended by the kindergarten teachers, to obtain safer and more reliable information, so as to accurately grasp the situation of young children, and conduct targeted and standardized safety education. Parents can also enrich their professional knowledge through professional documents promulgated by the state, such as "Guidelines for Kindergarten Education" and "Guide to Learning and Development for Children Aged 3-6". At the same time, parents should also learn more from the forms and methods of safety education carried out by kindergartens, so 
that they not only have a wealth of safety knowledge, but also present them in a way that children understand, accept, and love. Safety training can enhance parents' ability to predict danger and emergency response ability when danger comes, and reduce the frequency of family safety accidents and harm to young children. Therefore, qualified parents can also participate in safety education and training on different topics, so that the safety education knowledge they have acquired is not only broad, but also more in-depth.

\subsection{Optimize family safety education methods}

Parents should abandon the "mantra" style of education. This kind of verbal restraint and prohibition often keeps the courageous children deaf, and the cowardly children stay away. This curbs the child's nature to a certain extent and hinders his physical and mental health. Parents should adopt more flexible and vivid methods, and provide more opportunities for children to practice operations. By creating interesting situations, children can practice repeatedly, and eventually become "subconscious" so that they can naturally make correct behaviors when encountering danger. Furthermore, parents can use games to educate their children about safety, and they can also infiltrate some safety knowledge into games for education. For example, through the parent-child game "Where do I live", tell young children to be bold when they get lost, and remember their parents' names, work unit, phone number, home address and obvious architectural features of the surrounding environment. In this way, children's emotions of self-rescue are aroused, and children are encouraged to come up with specific methods of self-rescue, thereby improving their self-protection ability.

\subsection{Help young children improve their self-protection ability}

Parents should guide their children to participate in more sports exercises, for good physical fitness can reduce the occurrence of accidents to a certain extent. Only when children's own abilities are improved, can they truly protect themselves in dangerous situations. Toddlers are born with a wonderful relationship with nature. And they like to run in the wind and play in the sun. Therefore, parents should let children participate in outdoor activities as much as possible. In outdoor activities, not only should parents not restrict children's activities too much, they should also explain the correct way to play the game before the activity, and remind them of precautions. After the activity, the child's performance should be correctly evaluated, so that children can learn to abide by the rules and improve safety awareness. While strengthening children's physical exercise, parents should also cultivate good living habits for children. However, parents should realize that habit formation cannot be effective with one or two educations. In addition, children's consciousness and ability are worse when they are young. Therefore, in addition to requesting and teaching methods to children, parents should also pay attention to supervision and inspection, so that children can establish good living habits in their continuous labor practices, so as to truly play a role in self-protection.

Parents should be aware of the limitations of their own educational philosophy and educational strategies due to lack of professional knowledge. They should ask the teacher with an open mind and actively communicate with the teacher on the personality features and living habits of their children. Parents should also pay attention to the various parent-child safety education lectures and drills held in kindergartens to jointly witness their children's progress and accompany their children's healthy and happy growth.

\section{Conclusions}

This study uses questionnaire and interview methods to investigate the status quo of preschool safety education and finds that the current family safety education for preschool children has problems such as excessive protection of children by parents, delayed timing, and lack of comprehensive content. The main reasons for these problems include the deviation of parents' safety education concept, parents' insufficient understanding of children's physical and mental characteristics, parents' professional knowledge and skills to be improved, and the in-depth development of kindergarten home safety and 
mutual education activities. As the social environment becomes more and more complex, preschool safety education has become increasingly urgent. As one of the main positions of preschool safety education, the family should take on the responsibility of preschool safety education.

\section{Conflicts of Interest}

The author declares no conflicts of interest regarding the publication of this paper.

\section{References}

[1] Ministry of Education of the People's Republic of China. (2010). National Family Education Guidelines. http://www.moe.gov.cn/moe_1777/moe_1779/201007/t20100714_92936.html

[2] Cui G.X. (2015). Homeland Cooperation Research on Early Childhood Safety Education. Guangxi Normal University, Guilin.

[3] Cao M.Y. (2016). Research on the Status Quo of Safety Education for Children by Parents of 3-6 Years Old Children. Hebei University, Shijiazhuang.

[4] Gu R.F. (2014). On Health Education for Preschool Children. Jiangsu Education Press, Nanjing.

[5] Wang X.H. (2004). An Analysis of the Problem of Overprotection of Young Children. Education Guide (Part 2), (4): 13-15.

[6] Jiang Z.J. (2016). Using Parent-child Games to Open the Door to Traffic Safety Education. Early Education (Teacher Edition), (7): 80 -81.

[7] Deng X.L and Shi D.S. (2019). Safety Signs and Infant Safety Education. Preschool education research, (1): 9396. 